\title{
A FORMAÇÃO EM QUÍMICA DISCUTIDA COM BASE NOS MODELOS PROPOSTO POR ESTUDANTES DE PÓS-GRADUAÇÃO PARA O FENÔMENO DE DISSOLUÇÃO
}

\author{
Karina Aparecida de Freitas Dias de Souza e Arnaldo Alves Cardoso* \\ Departamento de Química Analítica, Instituto de Química, Universidade Estadual Paulista, CP 355, 14801-970 Araraquara - SP, \\ Brasil
}

Recebido em 16/10/07; aceito em 14/7/08; publicado na web em 15/12/08

\begin{abstract}
GRADUATION IN CHEMISTRY DISCUSSED IN RELATION TO GRADUATE STUDENTS' MODELS CONCERNING THE PHENOMENON OF DISSOLUTION. Mental models play an important role in the evolution of an individual's so-called knowledge. Using such representations, students can explain, foresee, and attribute causality to observed phenomena. In the case of Chemistry, the ability to work mentally with models assumes great importance, due to the microscopic component that is characteristic of this science. With the objective of exploring students' ability to work with models, 27 students of the Chemistry Institute of UNESP were asked to describe the mechanisms of dissolution, in water, of $\mathrm{NaCl}, \mathrm{HCl}$ and $\mathrm{HCN}$, as well as the partial dissolution of $\mathrm{I}_{2}$. Due to difficulties of access to complex descriptors of these processes, each student was asked to explain the phenomena using words and drawings. The results of these investigations were analyzed, and enabled construction of a framework representing the Chemistry students' theoretical training, especially with respect to their most important transferred skill: an ability to model the physical world.
\end{abstract}

Keywords: mental models; dissolution in water; Chemistry education.

\section{INTRODUÇÃO}

A complexidade da ciência moderna e dos processos através dos quais ela propicia a construção de novos conhecimentos reside na vinculação da teoria com o objeto pesquisado, com o fenômeno observado, através da experimentação, ou seja, ao aspecto teóricoabstrato associa-se, também, um aspecto empírico-concreto. Como observam Alfonso-Goldfarb e Beltran:

“(...)a realização de experimentos passaria a caracterizar a ciência moderna, desde suas origens. Entretanto, a visão que hoje se tem de experimento como poderoso meio de se interrogar a natureza foi construída a partir de uma série de debates... Os estudiosos passariam, a partir dos séculos XVI e XVII, a valorizar os experimentos, transformando as conotações expressas por autores medievais. Já durante os séculos XVIII e XIX, a forma de realizar observações, reproduzir e controlar experimentos centralizou intensos debates entre os pensadores daquela época, tanto no campo das ciências da matéria quanto no das ciências da vida, os quais gradativamente se especializavam" (p. 6). ${ }^{1}$

Ao processo de experimentação associa-se, agora, a instrumentação, e seu papel não está mais centralizado no estabelecimento da correspondência direta entre o real e o teórico, mas sim no estabelecimento de uma aproximação entre essas duas instâncias.

No conjunto dessa nova forma de pensar e construir ciência, então, o atributo de essencialidade passa da correspondência direta entre o teórico e o real, para a capacidade do primeiro proporcionar predições satisfatórias acerca de manipulações e intervenções no segundo. Em outras palavras, ao processo de idealização e elaboração de construtos teóricos atribui-se maior importância, dado que a construção de modelos passa a ser importante ferramenta para os "novos cientistas" e constituir a essência intelectual de seu trabalho.

*e-mail: acardoso@iq.unesp.br
Operando com modelos: considerações sobre o trabalho científico e a aprendizagem de ciências

Com o intuito de esclarecer o sentido atribuído ao termo "modelo" no presente trabalho, é importante destacar que esse pode assumir diferentes significados (e até sub-significados) dependendo do contexto e do objetivo do interlocutor quando dele fizer uso. No que se refere à sua utilização dentro das ciências naturais ele pode referir-se, por exemplo, a um modelo físico. É o caso da utilização de bolinhas e bastões para a representação de átomos e moléculas, ou da elaboração de um desenho para o mesmo fim. O termo pode também denotar um conjunto de equações matemáticas que permitem descrever e prever o comportamento de determinados sistemas. Em outras situações, o modelo pode ser uma representação imaginária de uma situação proposta ou objeto, o que veremos tratar-se de um modelo mental, tema de especial interesse para esse trabalho.

O importante, contudo, é a percepção de que, seja qual for o significado assumido para "modelo" na ciência, ele não pode ser considerado uma cópia, miniatura ou descrição fiel da realidade. Um modelo seria melhor definido como uma representação de um objeto, idéia ou processo, por meio de analogias. Ou seja, um modelo possui características físicas ou mentais que pode substituir ou ocupar o lugar de alguma coisa que ele representa em situações idealizadas.

Esse mecanismo de representações analógicas está sempre (muito) presente nas interações que estabelecemos com o mundo. Segundo Moreira, "As pessoas não captam o mundo exterior diretamente, elas constroem representações internas dele" ${ }^{2}$ Fazendo uso de teoria proposta por Johnson-Laird, a essas representações internas, que seriam a principal forma de raciocínio humano, é que se dá a denominação modelos mentais. ${ }^{3}$

A habilidade no manejo dos modelos mentalmente construídos é de extrema importância para a produção do conhecimento científico, pois são eles que permitem explicar, fazer previsões e atribuir causalidade aos eventos e fenômenos observados. ${ }^{4}$ Essa importância deve ser estendida igualmente a situações onde o objetivo é ensinar 
esse conhecimento produzido:

\begin{abstract}
"Quem aprende precisa ter acesso não apenas às experiências físicas, mas também aos conceitos e modelos da ciência convencional. $O$ desafio está em ajudar os aprendizes a se apropriarem desses modelos, a reconhecerem seus domínios de aplicabilidade, dentro desses domínios, a serem capazes de usá-los" (p. 34). ${ }^{5}$
\end{abstract}

Essa habilidade ganha especial destaque nos domínios da ciência Química: em trabalho publicado em 1982, Johnstone afirma que a Química pode ser estudada em, pelo menos, três níveis. ${ }^{6} \mathrm{O}$ primeiro, denominado macroscópico, refere-se àquilo que é possível ver e manusear, e que permite descrever as propriedades de um material ou sistema. O segundo é o nível representacional ou simbólico, no qual as substâncias e fenômenos químicos são representados por meio de símbolos, fórmulas e equações. O terceiro nível, denominado microscópico e mais sofisticado, compreende a "manipulação mental" de partículas (sub) microscópicas como átomos, íons e moléculas, com o intuito de explicar as observações pertencentes ao primeiro nível. Mortimer e colaboradores sugerem, ainda, denominação alternativa a esses três níveis, que passariam a ser designados fenomenológico, representacional e teórico-conceitual, respectivamente. ${ }^{7}$ Seja qual for a designação adotada, é a livre transição entre esses três níveis que fornece requisitos para que o químico, em seu percurso profissional, contemple em suas atividades os dois aspectos complementares dessa ciência : o prático, que envolve uma maneira especial de lidar com a matéria, e o teórico, com a preocupação maior de pensar sobre os fatos observáveis em termos de esquemas e modelos representativos. ${ }^{8}$

Permeados por essas convicções, vimos através deste trabalho procurar possíveis respostas para a seguinte questão: quais têm sido as contribuições dos cursos de formação para o desenvolvimento dessa habilidade tão importante e caracterizadora do profissional da Química?

Na busca de informações que subsidiem hipóteses para a questão levantada, apresentamos estudo acerca das habilidades no trabalho com modelos mentais e na sua utilização na discussão e previsão de situações relacionadas ao fenômeno de dissolução, evidenciadas por estudantes de pós-graduação do Instituto de Química da UNESP, campus Araraquara.

\section{DESENVOLVIMENTO DA PESQUISA}

Vinte e sete estudantes matriculados no programa de pós-graduação em Química (12 mestrandos e 15 doutorandos) do Instituto de Química da UNESP, oriundos de diferentes cursos de graduação, participaram da pesquisa. Apenas um deles (estudante 3) não era graduado em Química, sendo bacharel em Farmácia - Bioquímica. Cabe destacar que todos os estudantes estavam, no momento da realização da pesquisa, cursando a disciplina "Caracterização térmica de materiais", oferecida por docente lotado no departamento de Química Analítica do mesmo Instituto. A escolha desses estudantes deveu-se à facilidade de comunicação, uma vez que um dos pesquisadores cursava a disciplina no período em que a pesquisa foi desenvolvida e ao fato de que, em sua quase totalidade, os pós-graduandos desenvolviam seu projeto no departamento de Química Analítica, cujos temas de interesse muito comumente dependem do bom entendimento da "química de soluções".

Propôs-se aos estudantes uma atividade na qual o processo de dissolução de diferentes substâncias em água deveria ser descrito segundo seus aspectos microscópicos. As substâncias propostas foram: cloreto de sódio (composto iônico bastante solúvel em água), iodo (composto molecular parcialmente solúvel em água), ácido clorídrico (ácido forte) e ácido cianídrico (ácido fraco). A escolha da "dissolução" enquanto tema central da pesquisa está relacionada à recorrência do tema na vida escolar dos estudantes, e, principalmente, ao fato de que o entendimento qualitativo do processo de formação de soluções é base para o entendimento de outros fenômenos e conceitos, como propriedades químicas e físicas, reações e equilíbrio químico.

Solicitou-se que a descrição dos fenômenos fosse feita, em um primeiro momento, através da escrita e, num segundo momento, com a utilização de desenhos. Algumas propriedades das referidas soluções eram fornecidas, como a condução ou não de corrente elétrica, com o objetivo de auxiliar o desenvolvimento da atividade.

A opção pela utilização da linguagem escrita em associação à linguagem gráfica configura tentativa de maior aproximação dos modelos mentais que os estudantes apresentavam em relação ao tema frente à quase impossibilidade de acessarmos essa tão complexa forma de pensamento. Segundo Morris e Rouse, “(...) o acesso (às representações mentais) parece limitado ao senso de que as habilidades do pesquisador em capturar os modelos mentais são controladas pela inabilidade dos sujeitos verbalizarem seus modelos". ${ }^{9}$ Adicionalmente, diversos trabalhos encontrados na literatura propõem a utilização dessa ferramenta na avaliação de conhecimentos químicos (Yarroch ; Gabel e Samuel; Lythcott; Sanger; Vásquez et al. $).{ }^{10}$ Esses trabalhos baseiam-se na idéia de que a facilidade em esquematizar o mundo microscópico permite diferenciar os estudantes que, por algum motivo, mostram-se mais comprometidos com o entendimento de conceitos do que com a mera resolução de problemas. Ou, segundo Nakhleh, os que se envolvem mais com o "por que" da Química que com o "como". ${ }^{11}$ Dentre os artigos citados, o trabalho de Smith e Metz trata especificamente do fenômeno de dissolução e da caracterização de ácidos (ou bases) fortes e fracos. ${ }^{12}$ Porém, às questões propostas foram apresentadas respostas na forma de alternativas, o que indubitavelmente oferece certa limitação ao raciocínio do estudante. Além disso, as alternativas não consideravam algumas questões por nós consideradas importantes, como as interações soluto-solvente, por exemplo.

A utilização de desenhos foi, então, assumida como possível alternativa em busca da maior proximidade possível aos modelos mentais dos estudantes e de maior fidedignidade a suas idéias.

Recolhidos os dados, teve início nova empreitada: a elaboração de um sistema de análise das respostas obtidas. Uma primeira leitura do conjunto respostas escritas/ desenhos trouxe à tona um aspecto que acabou por determinar o procedimento adotado na categorização dos dados obtidos: as incoerências existentes entre as respostas escritas e os desenhos propostos. Nesse contexto, ora os desenhos contradiziam as afirmações das respostas escritas, ora traziam aspectos não mencionados nas mesmas, evidenciando uma riqueza conceitual imperceptível se realizada unicamente a avaliação das questões dissertativas.

Frente a essa observação, optou-se pela criação de "subcategorias" que permitissem a avaliação, em separado, das respostas escritas e dos desenhos. A comparação e combinação dessas subcategorias levariam a uma segunda categorização, dessa vez mais relacionada ao aprofundamento teórico-conceitual e adequação do mesmo à questão. Cabe destacar que o critério que conduziu a análise dos dados priorizou o aspecto relativo às interações soluto-solvente. Dessa forma, as respostas foram consideradas conceitualmente mais ricas à medida que explicitavam mais profunda e adequadamente essas relações. As subcategorias propostas estão descritas abaixo.

a) Respostas escritas: a.1. Ausência de resposta; a.2. Simples reprodução do enunciado proposto, sem preocupação com a explicação do fenômeno; a.3. Consideração da existência de algum tipo de interação soluto-solvente, sem descrição do 
mecanismo; a.4. Consideração e descrição das interações soluto-solvente, mas explicitando um mecanismo diferente do proposto pelo modelo científico; a.5. Consideração e descrição das interações soluto-solvente, explicitando um mecanismo de acordo com o modelo científico.

b) Desenhos: b.1. Ausência de resposta; b.2. Somente as partículas referentes ao soluto aparecem representadas; b.3. Tanto as partículas de soluto quanto as de solvente aparecem representadas. Não existe, porém, preocupação com as interações existentes entre elas; b.4. As interações soluto-solvente aparecem, ainda que de maneira não clara; b.5. As interações soluto-solvente são representadas de forma clara, mas segundo um modelo que difere do científico; b.6. Consideração das interações soluto-solvente, explicitando um mecanismo concordante com o modelo científico.

Conforme mencionado, após a análise e interpretação/categorização das respostas escritas e dos desenhos procedeu-se à comparação entre as informações escritas e pictóricas, com o intuito de verificar a coerência e complementaridade entre elas. Da combinação das subcategorias acima apresentadas, distribuímos os estudantes entre quatro posturas ou níveis interpretativos e explicativos, de acordo com sua maior ou menor habilidade de manipulação do nível teórico conceitual de explicação dos fenômenos químicos. É importante ressaltar que, em caso de dúvidas acerca das representações ou de possíveis contradições, os estudantes eram convidados a participar de uma pequena entrevista, com intuito de melhorar o entendimento acerca das respostas propostas.

Foram encontradas semelhanças entre os resultados obtidos nesse trabalho e os apresentados por Benarroch e Carmo, de modo que o tratamento dos dados agora discutidos foi em parte baseado nas análises propostas pelas autoras citadas. ${ }^{13-15}$ Conforme será apresentado posteriormente, as categorias propostas não correspondem a uma "rotulagem" do raciocínio do estudante, mas sim a uma postura por ele assumida diante de uma determinada questão.

$\mathrm{Na}$ seqüência, apresentamos as categorias propostas e exemplos.

\section{$\underline{1}^{a}$ Categoria - Predominância fenomenológica}

Alguns estudantes limitaram-se à confirmação das propriedades macroscópicas citadas no enunciado, atendo-se à descrição, apenas em nível fenomenológico, do que pode ser observado experimentalmente. Os desenhos propostos, por sua vez, representavam as partículas oriundas do soluto, apenas com o intuito de explicar a condução (ou ausência de condução) de corrente elétrica mencionada no enunciado, sem que fosse considerado o papel do solvente na dissolução, evidenciando a predominância de um raciocínio meramente funcional, não necessariamente embasado teoricamente. Em um dos casos, ainda, apenas as questões escritas foram respondidas, não ocorrendo a proposição dos desenhos.

Resultados representativos do nível explicativo predominantemente fenomenológico estão apresentados abaixo.

Estudante 4 - Resposta: $\mathrm{NaCl}_{(\mathrm{s})}+\mathrm{H}_{2} \mathrm{O} \rightarrow \mathrm{Na}^{+}+\mathrm{Cl}^{-}$. Este sal em água se dissocia formando íons $\mathrm{Na}^{+} \mathrm{e} \mathrm{Cl}$.Desenho proposto: Figura 1a

Estudante 6 - Resposta: Ao adicionar ácido cianídrico em água notaremos que a reação resultante irá gerar gases, porém sua coloração permanecerá incolor e sendo uma reação endotérmica o béquer irá esfriar. Desenho proposto: Figura 1c

Estudante 5 - Resposta: O iodo, $\mathrm{I}_{2}$, se dissocia em água e fica em a)
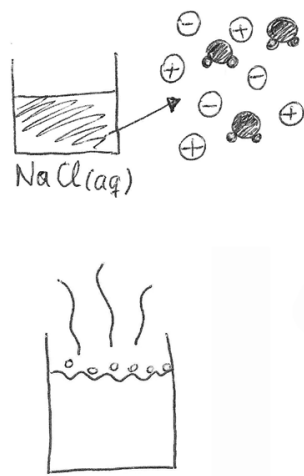

b)

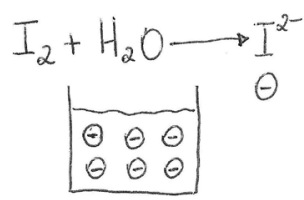

c)

e)

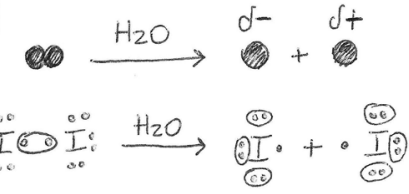

d)

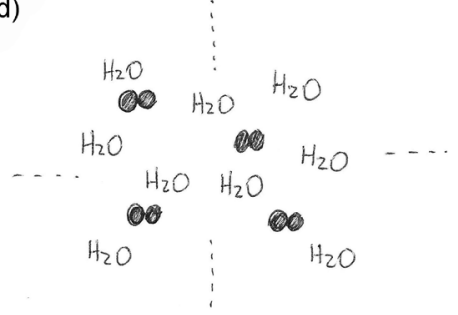

Figura 1. (a) Representação proposta pelo estudante 4 para a dissolução do cloreto de sódio em água; (b) representação proposta pelo estudante 5 para a dissolução parcial do iodo em água; (c) representação proposta pelo estudante 6 para a dissolução de ácido clorídrico em água; (d) representação proposta pelo estudante 15 para a dissolução parcial do iodo em água; (e) representação proposta pelo estudante 16 para a dissolução parcial do iodo em água

solução na forma de $\mathrm{I}^{2-}$, que na presença de $\mathrm{H}_{3} \mathrm{O}^{+}$não conduz corrente elétrica. Desenho proposto: Figura 1b

Faz-se importante, nesse momento, chamar a atenção do leitor para a (alarmante) ocorrência de explicações conceitualmente inadequadas, as quais lançam mão de concepções alternativas e errôneas variadas acerca dos conceitos envolvidos na explicação do fenômeno de dissolução. Na situação acima, é possível observar a interpretação inadequada não só do fenômeno de dissolução de uma substância molecular, mas também do próprio fenômeno de condução de corrente elétrica, dado que se afirma a não condução, mesmo havendo a presença de íons. A ocorrência desses erros conceituais, bem como a presença de respostas inadequadas ou excessivamente reducionistas, poderão ser observadas em outros exemplos.

\section{$2^{a}$ Categoria - Uma interpretação (pseudo) teórico-conceitual}

Nesta categoria foram agrupados os estudantes que, apesar de esboçarem tentativas de explicitação das interações soluto-solvente em suas respostas escritas e/ou desenhos, o fizeram de forma não clara (não houve a proposição de uma estrutura para essas interações) ou incoerente (respostas escritas que consideravam os aspectos microscópicos da formação de soluções associadas a desenhos que desconsideravam totalmente esse aspecto, ou que o faziam de maneira conceitualmente inadequada).

Estudante 15 - Resposta: Por se tratar de um composto covalente, a dissolução de iodo em água resulta na formação de moléculas discretas de $I_{2}$. Como não há formação de espécies iônicas, não há condução elétrica na solução. Desenho proposto: Figura 1d

Conforme descrito, em alguns casos o desenho proposto contradizia a explicação dada em palavras:

Estudante 16 - Resposta: $I_{2}$ é um sólido molecular onde a adição 
de água apenas envolve suas moléculas ("solvatam"), porém não é capaz de quebrar a ligação (neste caso, covalente) formada entre seus íons (molécula apolar; geometria linear) $\rightarrow$ não há diferença de eletronegatividade. Desenho proposto: Figura 1e

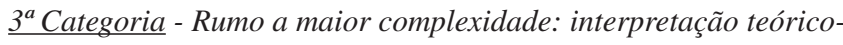
conceitual em desacordo com o modelo científico

Ainda que não se apresentassem concordantes com o modelo científico, algumas respostas evidenciaram um importante aumento na complexidade de raciocínio, se comparadas àquelas enquadradas nas categorias acima apresentadas. As interações soluto-solvente passam a ser consideradas tanto nas respostas escritas como nos desenhos ou, ainda que não aparecessem nas respostas dissertativas, um mecanismo de interação encontrava-se muito claramente explicitado no desenho. É nesse ponto, fundamentalmente, que esses estudantes diferem da categoria anterior, na qual os respondentes sugeriam a existência de uma interação, ainda que não estivesse explícita a forma a partir da qual a mesma era estabelecida.

Estudante 9 - Resposta: A água é uma molécula polar e isto faz com que ocorra uma interação com o "retículo cristalino" do $\mathrm{NaCl}$, fazendo com que cada átomo de $\mathrm{Na}^{+}$fique orientado com o oxigênio e $o \mathrm{Cl}^{-}$se oriente com os hidrogênios. Desenho proposto: Figura 2a

Estudante 18 - Resposta: O HCN é um ácido fraco devido ao H não ser muito disponível quando ligado ao $\mathrm{CN}^{-}$. A ligação em $\mathrm{HCN}$ é pouco polar, devido à pequena diferença de eletronegatividade entre H e C. O HCN dissolve-se pouco em água e a solução é fracamente condutora de corrente elétrica. Desenho proposto: Figura $2 \mathrm{~b}$

Nessa situação está evidenciada a concepção, também (muito comumente) apresentada por outros estudantes, de que a ocorrência da ionização apresenta-se como fenômeno decorrente da solubilização de um eletrólito. Ou seja, não existe dissolução sem que ocorra uma ionização (ou dissociação).

Apesar do uso indevido ou inconveniente de alguns conceitos, a maior complexidade de raciocínio desses estudantes é inegável. Em relação às inadequações em relação ao modelo científico, foi possível observar, corroborando com as discussões amplamente apresentadas na literatura, que a proposição de um modelo alternativo era ocasionada por concepções alternativas fortemente arraigadas na estrutura cognitiva do estudante, as quais inevitavelmente embasam suas construções teóricas, e sustentam sua coerência interna.

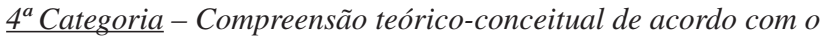 modelo científico}

Caracterizando uma quarta postura interpretativa, alguns estudantes propuseram respostas escritas e/ou desenhos que, além de consideram os aspectos microscópicos importantes para a descrição do fenômeno de dissolução, forneceram explicações coerentes com a visão conceitualmente aceita pela ciência.

Estudante 25 - Resposta: Embora o momento dipolar resultante do $I_{2}$ seja zero devido à ausência de eletronegatividade, esta molécula apresenta dois átomos grandes e "moles" capazes de sofrer polarização por um dipolo permanente (ex. $\left.\mathrm{H}_{2} \mathrm{O}\right)$. Então, as moléculas de $I_{2}$ acabam sendo solvatadas por água mas não ocorre rompimento da ligação. Portanto, não há geração de eletrólitos $\rightarrow$ ausência de corrente elétrica. Desenho proposto: Figura 2c

Conforme mencionado anteriormente, a proposta de categorização aqui apresentada assemelha-se, em alguns pontos, à apresentada por outros autores. Nesse contexto, acreditamos que a maior contribuição de nosso trabalho, além do maior enfoque no entendimento a)

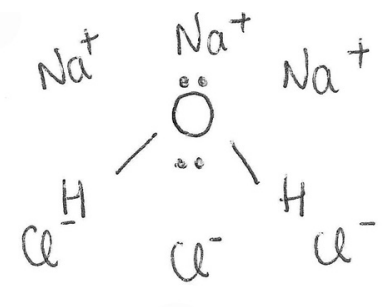

b)

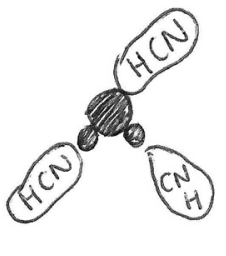

c)

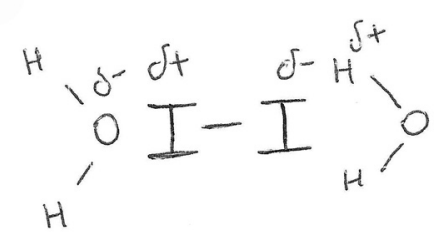

Figura 2. (a) Representação proposta pelo estudante 9 para a dissolução do cloreto de sódio em água; (b) representação proposta pelo estudante 18 para a dissolução do ácido cianídrico em água; (c) representação proposta pelo estudante 25 para a dissolução do iodo em água

teórico - conceitual (microscópico) desse fenômeno pelos estudantes, e da extensão dos resultados a estudantes de pós-graduação, está no fato de que os estudantes mostraram assumir diferentes posturas interpretativas frente às diferentes questões, isto é, o nível de interpretação do problema variava com a substância apresentada. A análise das respostas dissertativas e dos desenhos propostos pela estudante 10 ilustra claramente essa observação:

Questão 1: Dissolução do cloreto de sódio - NaCl - A dissolução do sal NaClocorre por meio da solvatação dos elementos que compõem o sal. O sal é composto por um cátion $\left(\mathrm{Na}^{+}\right)$e um ânion $\left(\mathrm{Cl}{ }^{-}\right) . \mathrm{Na}$ presença da água como solvente, ela vai hidratar esses íons, pois em solução eles não ficam na forma $\mathrm{NaCl}$. É possível conduzir corrente elétrica justamente devido à presença desses íons em solução.

Questão 2: Dissolução do iodo - $\mathbf{I}_{2}$ - O iodo irá se dissolver em água, mas não ocorrerá a formação de íons, ele fica na forma de molécula $\left(I_{2}\right)$ e não haverá "carga" livre na solução para ocorrer a condução de corrente elétrica.

Questão 3: Dissolução do ácido clorídrico - HCl - $O$ ácido clorídrico ( $\mathrm{HCl}$ ) quando dissolvido em água, ele dissocia-se $e^{17}$ totalmente, porque ele é um ácido forte. Portanto, também ocorre a formação de íons livres em solução, sendo possível a condução de corrente elétrica.

Questão 4: Dissolução do ácido cianídrico - HCN - $O$ ácido cianídrico (HCN) é considerado um ácido fraco, justamente porque sua dissociação em água é pequena, ou seja, não forma muitos íons em solução. Conseqüentemente, a condutividade será menor que a comparada com um ácido forte.

Ainda que a estudante tenha proposto representações iconográficas adequadas para a dissolução do cloreto de sódio e do ácido clorídrico em água, sendo considerados os processos de dissociação e ionização, respectivamente, bem como a solvatação dos íons gerados, os desenhos elaborados para o iodo e ácido cianídrico evidenciaram dificuldade de extrapolação do modelo de dissolução para situações discutidas com menor freqüência.

As respostas acima apresentadas sugerem aumento gradativo de dificuldade, que tem início com o cloreto de sódio, cuja dissolução geralmente aparece adequadamente discutida, passando pelo ácido clorídrico e ácido cianídrico, até chegar ao iodo, cuja representação aparece mais dificultada. Chega-se a observar desde a interpretação em nível teórico-conceitual de acordo com o modelo científico, no 
caso da dissolução do cloreto de sódio, até a presença da postura predominantemente fenomenológica, no caso do iodo.

Em vista das diferentes posturas interpretativas assumidas pelos estudantes frente às diferentes situações, optou-se por traçar um perfil geral dos mesmos frente às diferentes questões apresentadas, com base na quantificação das respostas por categoria. Os resultados obtidos estão resumidos no Gráfico 1. Nela, são apresentadas as distribuições dos estudantes pelos diferentes níveis explicativos frente às diferentes questões propostas.

A análise dos dados dispostos no Gráfico 1 revela que mesmo os estudantes que apresentaram bom desempenho na discussão do fenômeno de dissolução do cloreto de sódio, e até mesmo do ácido clorídrico, não o tiveram nas demais questões. Uma maior utilização de interpretações restritas aos aspectos fenomenológicos foi observada para as questões que tratavam da dissolução do ácido cianídrico e do iodo, sugerindo maior dificuldade por parte dos estudantes na interpretação e previsão dessas situações. Em contrapartida, quase a metade dos estudantes teve sucesso da descrição do fenômeno de dissolução do cloreto de sódio, exemplo mais comumente presente nas salas de aula e em livros texto. Essas observações permitem sugerir que existem obstáculos à extrapolação dos conceitos químicos envolvidos no fenômeno de dissolução a diferentes situações propostas.

A teoria de modelos mentais de Johnson-Laird, mencionada no início desse artigo, fornece subsídios interessantes para uma possível interpretação desses resultados. ${ }^{3}$ Nesse referencial, as representações internas, construídas pelos indivíduos em sua interação com o mundo, podem ser de três tipos, a saber: a) Proposições: representações de significado, que podem ser verbalmente expressas. A estrutura das proposições não mantém, portanto, uma relação analógica ao objeto ao qual elas estão referidas; b) Imagens: representações bastante específicas, que detêm muitos dos aspectos perceptivos / sensoriais de determinados objetos ou eventos; c) Modelos mentais: representações que estabelecem uma relação analógica com o objeto representado. Por esse motivo requerem certo grau de abstração.

Uma boa forma de compreensão do significado dos termos proposição, imagem e modelo é o exemplo apresentado por Moreira: a expressão "o quadro está na parede" poderia ser representada mentalmente como uma proposição, porque pode ser verbalmente expressa, como um modelo mental, de qualquer quadro em qualquer parede, ou como uma imagem de um quadro em particular em uma parede específica. ${ }^{3}$ Considerando a característica memorística e restrita das proposições e a grande especificidade das imagens, Johnson-Laird afirma que as pessoas, em um nível cognitivo mais sofisticado, operam em termos de modelos mentais. ${ }^{3}$

Pensando nos resultados obtidos, pode ser inferida a seguinte questão: os estudantes, em relação à interpretação do mundo físico, estariam construindo modelos, aplicáveis a situações distintas e mediadores de modificações e previsões acerca de seu funcionamento, ou estariam construindo meras imagens, fotografias engessadas dos fenômenos observados? Os dados recolhidos pela presente pesquisa infelizmente apontam para a segunda opção, sugerindo que é vivido um momento dentro das escolas de Química, que pede por maiores discussões acerca da qualidade do profissional formado, especialmente no que se refere à construção de uma forma de "pensar quimicamente" que os distancie da condição de meros executores de tarefas e os aproxime da condição de críticos e modificadores de sua prática.

De maneira intrigante (e acima de tudo preocupante) os pósgraduandos demonstraram não perceber a existência de obstáculos decorrentes de possíveis falhas formativas. Quando perguntados sobre alguma dificuldade encontrada na realização das atividades (escrita ou gráfica), as respostas dos estudantes muito comumente apontavam sempre para uma postura bastante segura em relação às a)
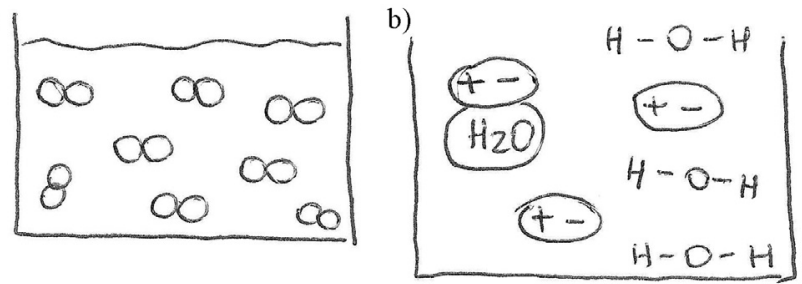

Figura 3. (a) Representação proposta pelo estudante 10 para a dissolução parcial do iodo em água; (b) representação proposta pelo estudante 10 para a dissolução do ácido cianídrico em água
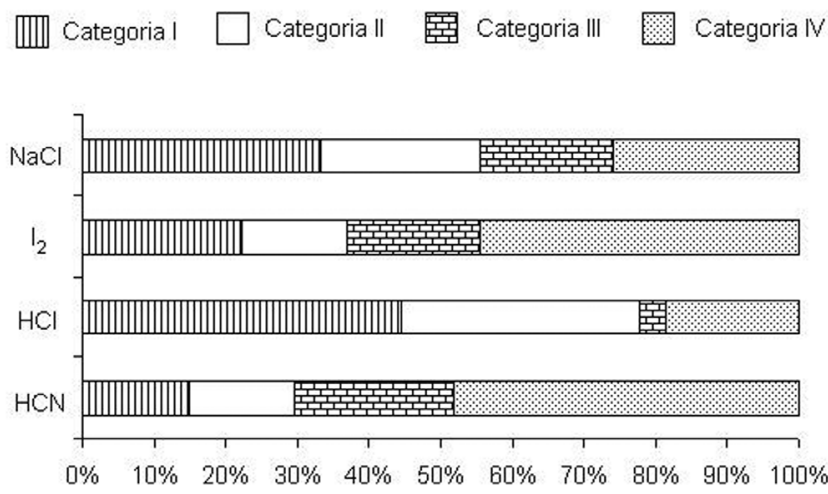

Gráfico 1. Percentual da ocorrência das diferentes posturas explicativas frente às diferentes questões propostas

respostas apresentadas. Apesar de referir-se à formação de professores de ciências, Carvalho e Gil-Pérez propõem grave diagnóstico, que parece se aplicar muito bem à situação agora apresentada: “(...) não só carecemos de uma formação mais adequada, mas não somos sequer conscientes de nossas próprias deficiências" (p. 14). ${ }^{17}$

As evidências trazidas pelas respostas dos estudantes reforçam a citação acima e nos levam à reflexão acerca do que os resultados obtidos com esse trabalho representam também para o futuro da formação em Química no país. Se considerarmos que "mais do que nunca, muitos profissionais das mais diferentes áreas buscam a docência no ensino superior como uma forma alternativa elou conjugada de inserção no mercado de trabalho", é impossível não nos preocuparmos com a postura, atuação e contribuição desses profissionais às gerações futuras, pelas quais serão responsáveis. ${ }^{18}$ Como reflexão, apresentamos o alerta Campanário e Otero para os riscos do recorrente mau uso que as Universidades fazem de suas atribuições e poder: ${ }^{19}$

"A Universidade, por seu efeito multiplicador, deve assumir uma cota significativa de responsabilidade na difusão e manutenção dessas concepções inadequadas fortemente arraigadas sobre a aprendizagem. $O$ ensino tradicional, baseado na rotineira tomada de notas e na recepção passiva dos conhecimentos, tão presente na maioria das salas de aula universitárias tem como conseqüência indesejável a transmissão aos alunos de toda uma ideologia implícita sobre o conhecimento científico e a aprendizagem. Esses alunos, que serão professores no futuro, reproduzem os métodos docentes aos quais foram submetidos".

\section{UM OLHAR PARA A FORMAÇÃO EM QUÍMICA - REFLEXÕES FINAIS}

As discussões mais atuais concernentes à formação do químico 
apresentam-se, sobretudo, focadas na preocupação com a formação interdisciplinar/generalista e a inserção desses profissionais no mercado tecnológico e industrial. ${ }^{20}$ Essas questões possuem, de fato, importância inquestionável, dado a variedade de sítios que podem ser ocupados pelo profissional químico na sociedade e a importância desse profissional para o desenvolvimento econômico da nação. Pouca ou quase nenhuma atenção, porém, é dedicada aos resultados alcançados ao longo das diferentes etapas do processo de aprendizagem vivenciado por esses estudantes, passando pelo ensino médio e pela graduação antes de chegar à pós-graduação. Que habilidades (não só técnicas, mas, principalmente, intelectuais) foram desenvolvidas por esses estudantes durante essa trajetória?

Nossos resultados sugerem que a resposta a essa pergunta repousa sobre aspectos quase exclusivamente concernentes às habilidades técnicas, os quais, infelizmente, predominam em detrimento das habilidades intelectuais. Nesse contexto, basta saber como produzir uma solução condutora de corrente elétrica, sem que, necessariamente, a técnica esteja impregnada pelo por que da ação e de seu efeito. A conseqüência direta é a incapacidade do exercício da previsão, da extrapolação de modelos explicativos de situações conhecidas a situações inesperadas. Essa constatação torna-se, no mínimo, preocupante se analisarmos as considerações de Maldaner e Piedade acerca da ciência Química: ${ }^{21}$

“... o cerne da ciência química é perceber, saber falar sobre e interpretar as transformações químicas da matéria (ou das substâncias) causadas pelo favorecimento de novas interações entre as partículas constituintes da matéria, nas mais diversas situações” (p.15 - grifo nosso).

Ou, ainda, se pensarmos que

"Como a Química está preocupada com as propriedades e transformações dos materiais, os químicos são essencialmente modeladores das substâncias que constituem esses materiais e de suas transformações". ${ }^{22}$

O que significa, então, a Química para esses estudantes? Parece não estar clara (ou pelo menos parece não estar sendo exercida) a função modelizadora do profissional químico, bem como sua atividade criadora e transformadora.

Devemos enfatizar que não se trata de rechaço à inegável importância da competência técnica, componente indiscutível e imprescindível à boa formação química, mas, sim, de preocupação com sua excessiva valorização dentro de um sistema de ensino e de um sistema de construção do conhecimento onde ainda é possível, com muita freqüência, observar a predominância do paradigma da racionalidade técnica. Não parece existir espaço para discussões acerca da natureza da Química e do pensamento químico, de seus objetos de estudo e de sua forma de refletir os fatos observáveis em termos de esquemas e modelos representativos.

As constatações dessa pesquisa tornam-se ainda mais preocupantes quando às reflexões acima desenroladas é somado o caráter de formação de pessoal para o ensino superior, papel esse essencialmente atribuído aos programas de pós-graduação.

É necessário ainda destacar que, associadas à dificuldade de manipulação e extrapolação de modelos explicativos, fazem-se preocupantemente presentes dificuldades puramente conceituais acerca de um dos fenômenos mais importantes e alicerçais do conhecimento químico: a dissolução. Concepções alternativas acerca das interações soluto-solvente, do fenômeno de condução de corrente elétrica e dos conceitos de dissociação e ionização, por exemplo, foram recorrentemente observadas. Constatações semelhantes e igualmente preocupantes decorreram de oportunidade de trabalho com concluintes do curso de licenciatura da mesma instituição e aproximam-se muito das concepções apresentadas por estudantes do ensino médio, evidenciando a instauração de um ciclo que o ensino universitário não tem conseguido encerrar. ${ }^{23}$

Os resultados desse trabalho apontam para urgente necessidade de que professores e instituições responsáveis pela formação desses futuros profissionais estejam cônscios de que a mediação da inserção dos aprendizes nas práticas e idéias da comunidade científica não é papel exclusivo de um ou outro momento da história escolar desses indivíduos. Ou seja, não é papel de um nível específico de ensino. Embrenhar-se na forma científica de raciocínio e construção de realidades teóricas é um processo que deve ser continuamente refeito, repensado e amadurecido ao longo de toda a trajetória escolar.

Para finalizar, citamos um trecho de Marques, ${ }^{24}$ que soa como um alerta à nossa comunidade, a quem compete o exercício das transformações:

"O conhecimento científico pretende ser sempre a reforma de ilusões, mas pode ele mesmo transformar-se em ilusão se estiver atento unicamente a si mesmo e pode levar a um reino de especialistas indispensáveis à operação da máquina social, destituídos, porém, da tomada de decisões, reduzidos à categoria de executantes mais ou menos respeitados".

Diante das reflexões desenvolvidas, cabe a nós, professores formadores e estudantes em formação, permear nossa prática com a questão fundamental: que profissionais queremos?

\section{AGRADECIMENTOS}

Aos estudantes que, muito pacientemente, possibilitaram o desenvolvimento da pesquisa, e ao CNPq pela bolsa de estudo concedida a K. A. F. D. Souza.

\section{REFERÊNCIAS E NOTAS}

1. Alfonso-Goldfarb, A. M. A.; Beltran, M. H. R., orgs.; O saber fazer e seus muitos saberes: experimentos, experiências e experimentações, Livraria da Física Ed./EDUC/FAPESP: São Paulo, 2006.

2. Moreira, M. A. Investigações em Ensino de Ciências 1996, 1, 3.

3. Johnson-laird, P, N.; Mental Models: towards a cognitive science of language, inference and consciousness, $1^{\text {st }}$ ed., Cambridge University Press: England, 1983.

4. Norman, D. A. Em Investigações em Ensino de Ciências; Borges, A. T., ed.; 1996, vol. 1, p. 1.

5. Driver, R.; Asoko, H.; Leach, J.; Mortimer, E.; Scott, P.; Quimica Nova na Escola 1999, n. 9, 31 .

6. Johnstone, A. H.; The School Science Review 1982, 64, 377.

7. Mortimer, E. F.; Machado, A. H.; Romanelli, L. I.; Quim. Nova 2000, $32,273$.

8. Chagas, A. P.; Como se faz química: uma reflexão sobre a química e a atividade do químico, $3^{\mathrm{a}}$ ed., Unicamp: Campinas, 2006.

9. Moris, N. M.; Rouse, W. B.; Psychol. Bull. 1986, 3, 349.

10. Yarroch, W. L.; J. Res. Sci. Teac. 1985, 22, 449; Gabel, D. L.; Samuel, K. V.; J. Chem. Educ. 1987, 64, 695; Lythcott, J.; J. Chem. Educ. 1990, 67, 249; Sanger, M. J.; J. Chem. Educ. 2000, 77, 762; Vásquez, T.; Angelini, M. C.; Guerrien, D.; Landau, L.; Educ. Qui. 2001, 12, 149.

11. Nakhleh, M. B.; J. Chem. Educ. 1993, 70, 52.

12. Smith, K. J.; Metz, P. A.; J. Chem. Educ. 1996, 73, 233.

13. Benarroch, B. A.; Enseñanza de las Ciencias 2000, 18, 235.

14. Carmo, M. P.; Marcondes, M. E. R.; Martorano, S. A. A.; Enseñanza de las Ciencias 2005, extra, 1

15. Benarroch ${ }^{13}$ pesquisou as percepções da natureza corpuscular da 
matéria apresentadas por estudantes em diferentes níveis de ensino, sugerindo a existência de 5 níveis explicativos concernentes à maior ou menor habilidade na proposição de explicações em nível microscópico. O nível 1 correspondia aos estudantes restritos ao observável, cuja explicação para o fenômeno proposto não passava de simples descrição da alteração observada, e o nível 5, aos que não só mostravam habilidade no raciocínio mental com partículas microscópicas, como também propunham explicações condizentes com os modelos científicos. $\mathrm{Carmo}^{14}$, por sua vez, utilizou a categorização proposta por Benarroch em estudo sobre a evolução conceitual de estudantes do ensino médio acerca do tema "soluções".

16. A confusão entre os conceitos de dissociação e ionização também foi bastante presente nas respostas dos estudantes.

17. Carvalho, A. M. P.; Gil-Pérez, D.; Formação de professores de ciências,
Cortez: São Paulo, 1993.

18. Arroio, A.; Quim. Nova 2006, 29, 1387.

19. Campanario, J. M.; Otero, J. C.; Enseñanza de las Ciencias 2000, 18, 155.

20. de Andrade, J. B.; Cadore, S.; Vieira, P. C.; Zucco, C.; Pinto, A. C.; Quim. Nova 2004, 27, 358; Rebouças, M. V.; Pinto, A. C.; de Andrade, J. B.; Quim. Nova 2005, 28 Suplemento, S14.

21. Maldaner, O. A.; Piedade, M. C. T.; Quimica Nova na Escola 1995, n. 1,15 .

22. Justi, R.; Gilbert, J. K.; Sci. Educ. 1999, 8, 287.

23. Souza, K. A. F. D.; Dissertação de mestrado, Universidade Estadual Paulista, Brasil, 2007.

24. Marques, M. O.; Conhecimento e educação, Unijuí: Ijuí, 1988. 